\title{
Microinvasive Breast Carcinoma
}

National Cancer Institute

\section{Source}

National Cancer Institute. Microinvasive Breast Carcinoma. NCI Thesaurus. Code C40374.

Ductal carcinoma in situ of the breast with minimal stromal invasion. Lymph node involvement is uncommon and the prognosis is generally good. 